\title{
Developmental expression of p97/VCP (Valosin- containing protein) and Jab1/CSN5 in the rat testis and epididymis
}

\author{
Sevil Cayli ${ }^{* *}$, Seda Ocakli ${ }^{1}$, Fikret Erdemir ${ }^{2}$, Ufuk Tas $^{3}$, Huseyin Aslan ${ }^{1}$, Tamer Yener ${ }^{4}$ and Zafer Karaca ${ }^{1}$
}

\begin{abstract}
Background: The ubiquitin proteasome system (UPS) is a key player in regulating many cellular processes via proteasomal degradation of ubiquitinated proteins. Recently published data show that Jab1/CSN5 interacts with p97NCP and controls the ubiquitination status of proteins bound to p97NCP in mouse and human cells. However, coexpression of p97NCP and Jab1/CSN5 in the developing rat testis and epididymis has not previously been studied.

Methods: Testicular and epididymal tissues from 5-, 15-, 30-, and 60-day-old rats were examined by immunohistochemistry and Western blotting. Colocalisation of proteins was determined by immunofluorescence microscopy.

Results: In the 5-day-old rat testis, p97NCP and Jab1/CSN5 were specifically expressed in gonocytes. The expression of p97NCP and Jab1/CSN5 significantly increased at day 15 and was found in spermatogonia, Sertoli cells and spermatocytes. In 30- and 60-day-old rat testes, p97NCP indicated moderate to strong expression in Sertoli cells, spermatogonia, round and elongating spermatids. However, moderate to weak expression was observed in spermatocytes. Jab1/CSN5 showed strong expression in spermatogonia and spermatocytes, while relatively moderate expression was observed in round and elongating spermatids in 30- and 60-day-old rat testes. In contrast, in the epididymis, the expression of both proteins gradually increased from 5 to 60 days of age. After rats reached 2 weeks of age, the expression of both proteins was mostly restricted to the basal and principal cells of the caput epididymis.
\end{abstract}

Conclusions: Our study suggests that p97NCP and Jab1/CSN5 could be an important part of the UPS in the developing rat testis and epididymis and that both proteins may be involved in the regulation of spermatogenesis and epididymal epithelial functions.

\section{Background}

The testis has the specific function of generating spermatozoa from precursors called spermatogonia after an intricate series of divisions [1]. This process takes place within the seminiferous epithelium, which is a complex structure composed of germ cells with radially oriented supporting cells termed Sertoli cells. In postnatal animals, spermatogenesis is initiated in the testes when gonocytes resume proliferation, migrate to the seminiferous tubule basal membrane and differentiate into spermatogonial

\footnotetext{
* Correspondence: sevilcayli@yahoo.com

'Department of Histology and Embryology, Faculty of Medicine,

Gaziosmanpasa University, Tokat, Turkey

Full list of author information is available at the end of the article
}

stem cells [2]. The postnatal phase is divided into three main stages: 1) mitotic proliferation of spermatogonial stem cells and premeiotic differentiation of spermatogonia into diploid primary spermatocytes; 2) meiotic differentiation of primary spermatocytes into haploid early, round spermatids; and 3) spermiogenesis, a cellular and nuclear reorganisation process that differentiates spermatids into spermatozoa [3].

The epididymis provides an adequate environment for the final maturation of sperm [4-6]. During embryonic and postnatal development of the testis and epididymis, regulated proteolysis and organelle degradation are required [7-9]. The ubiquitin proteasome system (UPS) is a developmentally regulated and highly substrate-

\section{()


specific pathway for the removal of damaged and aberrant proteins. It is well known that the UPS fulfils necessary requirements for sperm cell differentiation inside the testicular seminiferous tubules and cell cycle control throughout spermatogenesis and fertilisation in adult males. Moreover, the ubiquitin-activating enzymes (E1), ubiquitin-conjugating enzymes (E2), ubiquitin ligase (E3) and some proteasomal subunits are expressed during spermatogenesis and postnatal testicular development [10-13].

In the male reproductive system, the UPS contributes to gamete quality control mechanisms, carrying out selective spermatogonial removal at the haploid phase of spermatogenesis [14], protein and organelle degradation during spermiogenesis $[8,15]$, and the tagging defective spermatozoa with ubiquitin in the epididymis $[7,16]$. For these reasons, exploring the expression of proteins that are the components of the UPS may lead to advances in understanding the biology of the testis and epididymis.

In the ATP-dependent ubiquitin pathway, the attachment of ubiquitin to a target protein, referred to as ubiquitination, is carried out by E1, E2 and E3 [17]. The main purpose of ubiquitination is to deliver the ubiquitinated proteins to a cellular trash bin, a lysosome, an autophagosomal vacuole, or a $26 \mathrm{~S}$ proteasome. Ubiquitinated proteins can either be transferred directly to the proteasome or indirectly transferred via p97/Valosincontaining protein (VCP), a member of the ATPase super-family associated with diverse cellular activities (AAA-ATPase). p97/VCP has been associated with a wide variety of essential cellular protein pathways, including nuclear envelope reconstruction, cell cycle regulation, Golgi reassembly, suppression of apoptosis, DNA damage responses, maturation of autophagosome and sperm capacitation [18-26]. In addition, during endoplasmic reticulum-associated degradation, p97/VCP dislodges ubiquitinated proteins from the endoplasmic reticulum (ER) and chaperones them to the cytosol for proteasomal degradation [27]. For ubiquitination of misfolded proteins in the ER, interaction with $\mathrm{p} 97 / \mathrm{VCP}$ is required [28]. Moreover, it has recently been shown that the COP9 signalosome (CSN) interacts in an ATPdependent manner with p97/VCP and controls the ubiquitination status of proteins bound to p97/VCP [29].

The CSN, which is involved in the ubiquitin/proteasome system, contains eight core subunits (CSN1-8), like the proteasome lid complex. CSN5 (also known as Jab1) facilitates the $26 \mathrm{~S}$ proteasome-dependent degradation of several proteins, including p27Kip, luteinising hormone receptor (LHR), p53, oestrogen receptor, Smad4, Smad7, Id1, Id3, and I $\kappa$ B $\alpha$ [30-35]. The JAMM (JAB1/MPN/Mov34 metalloenzyme) domain present in Jab1/CSN5 exhibits deubiquitinase activity regulating ubiquitinlated protein sorting when associated with the
CSN [36]. In addition to its role in the UPS, Jab1/CSN5 regulates many signalling pathways, such as transforming growth factor (TGF) $-\beta$ signalling, cell proliferation, apoptosis and DNA repair [37].

Although it seems clear that the UPS is fundamentally required for the male reproductive system, there currently exists no information on the colocalisation patterns of $\mathrm{p} 97 / \mathrm{VCP}$ and Jab1/CSN5 and their possible roles in the developing rat testis and epididymis. Therefore, the goal of this study was to assess the developmental expression of p97/VCP and Jab1/CSN5 and to show the cellular localisation of both complexes in rat testis and epididymis. For this reason, we analysed the expression of $\mathrm{p} 97 / \mathrm{VCP}$ and Jab1/CSN5 in rat testis and epididymis during postnatal development using immunohistochemistry, immunofluorescence and Western blot techniques.

\section{Methods}

\section{Animals and tissue preparation}

After obtaining approval from the local ethics committee (2010-HADYEK-012), twenty-four male Wistar albino rats at postnatal ages of 5, 15, 30 and 60 days (six rats per group), i.e., corresponding to infantile (5 day), prepubertal (15 day), pubertal (30 day), and adult (60 day) periods, were obtained from the Gaziosmanpasa University Experimental Animal Research Laboratory. The rats were cared in the laboratory according to institutional guidelines and the Guide for Care and Use of Laboratory Animals of the National Research Council. All rats were observed for several days to ascertain their health status before sample collection. Pups were reared with their dams. They were maintained in a temperature-controlled room $\left(20-23{ }^{\circ} \mathrm{C}\right)$ on a $12 \mathrm{~h}$ light/dark cycle with food (commercial rat chow) and fresh water available adlibitum. Six rats of the same age were killed by administration of an overdose of sodium pentobarbital $(150 \mathrm{mg} / \mathrm{kg}$, i.p.) before removal of the testis and epididymis. Epididymes were dissected and subdivided into three anatomical regions: the caput $(\mathrm{CT})$, corpus $(\mathrm{CS})$ and cauda (CA) epididymis. One testis and epididymis from each animal were fixed in Bouin's fluid for $12 \mathrm{~h}$ immediately upon collection, then dehydrated and embedded in paraffin for histochemistry and immunohistochemistry experiments (see below). The contralateral testis and epididymal regions from each animal were snap frozen in liquid nitrogen and strored at $-80^{\circ} \mathrm{C}$ for Western blotting.

The definition of the stages and cell types with respect to the cycle of the seminiferous epithelium in adult testis was determined as previously published $[38,39]$. Germ cells were distinguished as being spermatogonia, spermatocytes, round and elongating spermatids based on their morphology and position in the seminiferous 
epithelium [40-42]. To spesificially identify mature Sertoli cells, p2 $7^{\text {kip1 }}$ immunostaining was performed at days 30 and 60 testis and cytokeratin 18 immunostaining were used to determine immature Sertoli cells at days $15[43,44]$.

\section{Immunohistochemistry}

For immunohistochemical analysis, $5 \mu \mathrm{m}$-thick serial sections were collected on poly-L-lysine-coated slides (Sigma-Aldrich, St. Louis, MO, USA) and incubated overnight at $56{ }^{\circ} \mathrm{C}$. Tissue sections were deparaffinised in xylene and rehydrated in a graded series of ethanol. Sections were then treated in a microwave oven in 10 $\mathrm{mM}$ citrate buffer, $\mathrm{pH} 6.0$ and left to cool for $20 \mathrm{~min}$. After three washes in phosphate buffered saline (PBS), endogenous peroxidase activity was quenched by $3 \%$ hydrogen peroxide in PBS for $20 \mathrm{~min}$., and the sections were washed again three times in PBS. The sections were then incubated in a blocking serum (Ultra $\mathrm{V}$ Block, TP-060-HL; NeoMarker, Fremont, CA, USA) for $10 \mathrm{~min}$. to block non-specific binding. Subsequently, sections were incubated overnight at $4{ }^{\circ} \mathrm{C}$ with following primary antibodies: mouse monoclonal p97/VCP (MA3004, 1: 500, Affinity BioReagent, USA), Jab1/CSN5 (sc9074, 1: 200, Santa Cruz Tech, USA), p27 ${ }^{\text {kip } 1}$ (sc-1641, 1: 100, Santa Cruz Tech, USA), p27 $7^{\text {kip } 1}$ (sc-776, 1: 100, Santa Cruz Tech, USA), cytokeratin 18 (sc-58729, 1: 200, Santa Cruz Tech, USA), p97/VCP (sc-20799, 1: 200, Santa Cruz Tech, USA) and Jab1/CSN5 (ab495, 1: 250, Abcam, UK). The sections were then washed three times in PBS and incubated with biotinylated antimouse (BA-9200; 1:400 Dilution; Vector Laboratories, Burlingame, CA) and biotinylated anti-rabbit (BA-1000; 1:400 Dilution; Vector Laboratories) secondary antibodies for $45 \mathrm{~min}$. at room temperature. After three washes with PBS, the antigen-antibody complexes were detected using a streptavidin-peroxidase complex (TP060-HL; LabVision, Fremont, CA, USA) for $15 \mathrm{~min}$., followed by three rinses with PBS. Bound peroxidase was developed with 3-amino-9-ethylcarbazol (AEC) (ScyTek Laboratories, USA) chromogen, and sections were counterstained with Mayer's hematoxylin (ScyTek Laboratories, Utah, USA) and mounted with Permount (Fisher Chemicals, Springfield, NJ, USA) on glass slides. For controls, sections were treated with the appropriate isotype of mouse IgG or rabbit IgG, depending on the primary antibody used, which was diluted to the same final protein concentration as the primary antibody. Photomicrographs were collected with a Leica microscope (Leica DM2500, Nussloch, Germany).

\section{Double immunofluorescence}

To identify colocalisation of proteins, immunofluorescence was performed. Both primary antibodies (rabbit
anti-Jab1/CSN5 and mouse anti-p97/VCP, mouse antip97/VCP and rabbit anti-p27 ${ }^{\text {kip } 1}$, mouse anti-Jab1/CSN5 and rabbit anti-p27 ${ }^{\text {kip } 1}$ ) were applied simultaneously and incubated overnight at $4^{\circ} \mathrm{C}$. After rinsing in PBS, sections were incubated with FITC-conjugated goat antirabbit secondary antibody (at a 1:200 dilution, Millipore, USA) and rhodamine-conjugated goat anti-mouse secondary antibody (at a 1:500 dilution, sc-2092, Santa Cruz Biotechnology, USA) for 1 hour at room temperature. Thereafter, all sections were rinsed in PBS and nuclei were stained with DAPI (Invitrogen, Molecular Probes, D-1306). Fluorescence images were taken with a Nikon microscope (Nikon E600, Germany).

\section{H-SCORE analysis}

Evaluation of the immunohistochemical labelling was performed using $\mathrm{H}$-SCORE analyses as previously described [45]. The intensities of the p97/VCP and Jab1/CSN5 immunoreactivities were evaluated semiquantitatively using the following intensity categories: 0 (no staining), 1+ (weak but detectable staining), 2+ (moderate or distinct staining), and 3+ (intense staining). For each tissue, an H-SCORE value was derived by calculating the sum of the percentages of cells that stained at each intensity category and multiplying that value by the weighted intensity of the staining using the Formula H-SCORE: $\Sigma \mathrm{Pi}(\mathrm{i}+\mathrm{l})$, where ' $\mathrm{i}$ ' represents the intensity scores and 'Pi' is the corresponding percentage of cells. For each slide, five randomly selected areas were evaluated under a light microscope $(40 \mathrm{x}$ objective), and the percentage of cells exhibiting each intensity within these areas was determined at different times by two investigators who were not informed about the type and source of the tissues. The average score of both observers was used.

\section{SDS-PAGE and Western blot analyses}

Total testicular and epididymal proteins were extracted using modified RIPA buffer (1\% NP-40; $0.25 \%$ sodium deoxycholate; $150 \mathrm{mM} \mathrm{NaCl}$; $1 \mathrm{mM}$ EDTA; $1 \mathrm{mM}$ PMSF; $1 \mathrm{mg} / \mathrm{ml}$ each of aprotinin, leupeptin, and pepstatin; $1 \mathrm{mM} \mathrm{Na} 3 \mathrm{VO} 4$; and $1 \mathrm{mM} \mathrm{NaF}$ in $50 \mathrm{mM}$ Tris$\mathrm{Cl}, \mathrm{pH}$ 7.4) and quantitated using the Bradford procedure (Bio-Rad, Hercules, CA). Then, 40- $\mu$ g samples were separated by $8 \%$ SDS-PAGE and electroblotted onto a nitrocellulose membrane (Bio-Rad Laboratories). The membrane was blocked with $5 \%$ non-fat dry milk in TBS containing $0.1 \%$ Tween 20 (TBS-T) for $1 \mathrm{~h}$ to reduce non-specific binding. Subsequently, the membrane was incubated for $1 \mathrm{~h}$ with primary antibodies against p97/VCP (MA3-004, Affinity BioReagent, USA, 1:10,000 in 5\% non-fat dry milk), Jab1/CSN5 (sc-9074, Santa Cruz Biotechnology, 1:500 in 5\% non-fat dry milk) and $\beta$-actin (sc-47778, C4; Santa Cruz Biotechnology 
Inc., $0.05 \mathrm{mg} / \mathrm{ml}$ in $5 \%$ non-fat dry milk). The membrane was washed with TBS-T for $1 \mathrm{~h}$ and incubated with horseradish peroxidase-conjugated anti-mouse and anti-rabbit secondary antibodies (Vector Laboratories) diluted in 5\% non-fat dry milk in TBS-T. Bound secondary antibodies were visualised using an enhanced chemiluminescence substrate (GE Healthcare). Immunoblot bands for $\mathrm{p} 97 / \mathrm{VCP}$, Jab1/CSN5 and $\beta$-actin were quantified using an Alpha DigiDoc 1000 gel documentation unit (Alpha Innotech Corporation, CA, USA). The optical density (OD) values for the p97/VCP and JAb1/ CSN5 bands were divided by the OD values of cognate $\beta$-actin bands to normalise the OD values for loading differences.

\section{Statistical analysis}

The Mann-Whitney $U$-test was employed for comparison of independent groups of samples, and KruskallWallis analysis with the Dunn posthoc test was performed for multiple comparisons of independent groups of samples. A $P$-value of less than 0.05 was considered to indicate a statistically significant difference. Statistical calculations were performed using SigmaStat for Windows, version 3.5 (Jandel Scientific Corp., San Rafael, CA).

\section{Results}

\section{Cellular localisation of p97/VCP and Jab1/CSN5 in the developing rat testis}

Immunohistochemical analysis of 5-day-old rat testes revealed that $\mathrm{p} 97 / \mathrm{VCP}$ was mainly localised to nuclear and cytoplasmic regions of gonocytes in the lumen of the seminiferous tubules (Figure 1A). No immunoreactivity was detected in somatic cells, though some interstitial cells showed immunopositivity for p97/VCP (Figure 1A). In the 15-day-old rat testis, spermatogonia at the basal membrane, Sertoli cells and spermatocytes were positive for p97/VCP (Figure 1B, Table 1). Additionally, interstitial cells showed weak to moderate immunostaining for p97/VCP at day 15 (Figure 1B). The staining intensity and the number of cells positively stained for p97/VCP significantly increased by day 15 , coinciding with the appearance of leptotene spermatocytes [39] (Figure 1B and 1M). The other cell types present in the 30-day-old rat testis, specifically round and elongating spermatids, also expressed p97/VCP (Figure $1 \mathrm{C}$ and 1D). Additionally, supporting Sertoli and peritubuler myoid cells, interstitial cells showed relatively moderate expression of $\mathrm{p} 97 / \mathrm{VCP}$, reaching the highest expression level at day 30 (Figure 1C-D and $1 \mathrm{M}$ ). In adult rat (60 day) testis, p97/VCP indicated moderate to strong expression in the Sertoli cells, spermatogonia, round and elongating spermatids; however, spermatocytes showed moderate to weak expression of p97/VCP
(Figure 1E-F, Table 1). The staining intensity and the number of p97/VCP-positive cells were found to be the same in all stages of seminiferous tubules in the adult rat testis. There was no immunoreactivity observed on negative control slides that were treated with the isotype mouse antibody instead of the p97/VCP primary antibody at the same final concentration (Figure 1A, 1C, inserts).

In the 5-day-old rat testis, Jab1/CSN5 showed moderate immunolabelling in gonocytes (Figure 1G). The staining intensity and the number of Jab1/CSN5-positivite cells were significantly increased in the 15-day-old rat testis compared to the 5-day-old rat testis (Figure $1 \mathrm{H}$ and $1 \mathrm{M})$. In the 15-day-old rat testis, Jab1/CSN5 localised strongly in spermatogonia and spermatocytes, but Sertoli cells presented only moderate to weak immunostaining (Figure $1 \mathrm{H}$, and Table 1). In the 30day-old rat testis, spermatogonia, spermatocytes, round and elongating spermatids, and Sertoli and interstitial cells were positively labelled with Jab1/CSN5, presenting the highest expression level observed (Figure 1I, Table 1).

In the 60-day-old rat testis, Jab1/CSN5 showed stronger nuclear staining in spermatogonia and moderate cytoplasmic staining in spermatocytes at stages 8-12 (Figure 1J-L). However, the acrosomes of round spermatids at stages 6-8 and the heads of elongating spermatids at stages 1-5 and 9-14 displayed relatively weak immunostaining for Jab1/CSN5 (Figure 1K, 1L). A few interstitial cells and Sertoli cells presented weak labelling for Jab1/CSN5. No immunoreactivity was detected on control slides (Figure 1G, $1 \mathrm{H}$ and $1 \mathrm{~L}$, inserts). According to $\mathrm{H}$-SCORE analysis, the expression of both Jab1/CSN5 and p97/VCP significantly increased from day 5 to day 30 in the testis, whereas no significant differences were found between day 30 and day 60 testes (Figure 1M).

Immunoexpression of immature and mature Sertoli cell markers such as cytokeratin 18 and p27 ${ }^{\text {kip } 1}$ was used to confirm whether p97/VCP and Jab1/CSN5 was expressed in Sertoli cells at days 15, 30 and 60 days of rat testis (Figure 2A-F). At days 15, Sertoli cells were immunopositive for cytokeratin 18 (Figure 2A). At days 30 and $60, \mathrm{p} 27^{\mathrm{kip} 1}$ was found to be expressed in the mature Sertoli cells (Figure $2 \mathrm{~B}$ and $2 \mathrm{C}$ ). Moreover, p2 $7^{\text {kip1 }}$ was colocalised with p97/VCP (Figure 2D-F) and Jab1/CSN5 (Figure 2G-I) in the mature Sertoli cells.

\section{Cellular localisation of p97/VCP and Jab1/CSN5 in the developing rat epididymis}

In the 5-day-old rat epididymis, p97/VCP immunostaining was found in the CT, CS and CA epididymis. Epithelial cells of epididymis were positively labelled for p97/VCP (Figure 3A-C). p97/VCP immunoreactivity showed no uniformity in different regions of the 


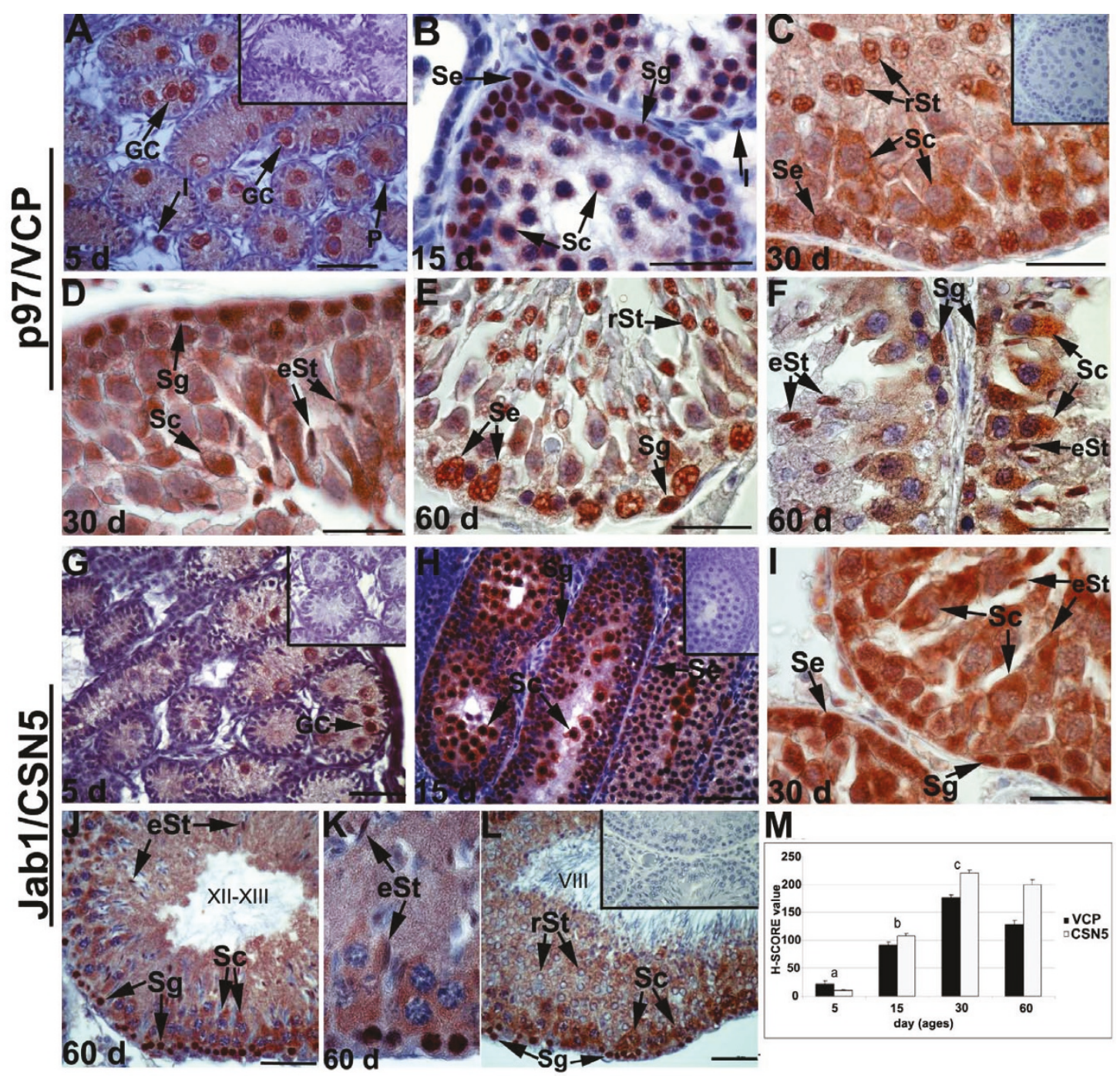

Figure 1 Localisation of p97/VCP and Jab1/CSN5 in the developing rat testis. Immunohistochemistry was used to show the cellular localisation of p97/NCP and Jab1/CSN5 in the testis at days $5(A, G), 15(B, H), 30(C, D, I)$, and $60(E, F, J, K, L)$ after birth. The negative controls ( $A, C, G, H$, L, inserts). A: Positive staining of p97NCP expression was demonstrated in the nuclear and cytoplasmic regions of gonocytes (GC) at day 5. Interstitial cells (I) show weak immunoreactivity, and peritubuler cells (P) present no immunoreactivity. B: p97NCP is highly expressed in spermatogonia (Sg), spermatocytes (Sc) and Sertoli cells (Se) at day 15. Some I show moderate immunostaining for p97NCP. C, D: Elongating (eSt) and round (rSt) spermatids, Se and Sg show moderate to strong immunostaining for p97NCP, while cytoplasm of Sc are moderately labelled with p97NCP. E, F: In the adult testis, p97NCP is weakly to moderately expressed in the cytoplasm of Sc, whereas Se, Sg, rSt and eSt are moderate to strong immunopositive for p97NCP. G: Moderate Jab1/CSN5 expression is seen at day 5 in GC. H: Jab1/CSN5 is strongly expressed in Sg and Sc while Se exhibit moderate expression at day 15. I: Sg, Sc, eSt and Se show moderate to strong immunostaining for Jab1/CSN5. J-L: In the adult testis, Jab1/CSN5 is strongly expressed in Sg and Sc, while rSt and eSt show weak to moderate immunostaining for Jab1/CSN5. Roman numerals indicate stages of the seminiferous epithelial cycle. M: H-SCORE of the p97NCP and Jab1/CSN5 immunostaining intensities in the developing rat testis. The data are represented as the means \pm SEM. a: $p<0.05$, day 5 vs. days 15,30 and 60 , b: day 15 vs. day 5 and day 30, c: day 30 vs. days 5 and 15. Scale bars: $50 \mu \mathrm{m}$.

epididymis, and high levels of expression were observed in CS at day 5 (Figure 3B). However, p97/VCP expression was higher in the $\mathrm{CT}$ and CS epididymis compared to the CA epididymis from day 15 to day 60 (Figure 3D-L, Table 2). p97/VCP immunostaining was seen in both the basal and principal cells of the adult rat epididymis (Figure 3J-L, Table 2). Moreover, in the lumen of the epididymis, spermatozoa presented weak staining for p97/VCP at day 60 (Figure 3L).

In 5-day-old rat epididymes, Jab1/CSN5 immunopositivity was detected in the $\mathrm{CT}, \mathrm{CS}$ and $\mathrm{CA}$ regions (Figure 4A-C). Although some epithelial cells showed no immunoreactivity, Jab1/CSN5 was expressed in both the principal and basal cells at day 15, 30 and 60 in the 
Table 1 Localisation of Jab1/CSN5 and p97/VCP in rat testis

\begin{tabular}{|c|c|c|c|c|c|c|c|c|c|c|c|c|c|c|}
\hline & \multicolumn{2}{|c|}{ GC } & \multicolumn{2}{|c|}{$\mathrm{Sg}$} & \multicolumn{2}{|c|}{ Sc } & \multicolumn{2}{|c|}{ rSt } & \multicolumn{2}{|c|}{ eSt } & \multicolumn{2}{|c|}{$\mathrm{Se}$} & \multicolumn{2}{|c|}{1} \\
\hline Postnatal Day & Jab1 & VCP & Jab1 & VCP & Jab1 & VCP & Jab1 & VCP & Jab1 & VCP & Jab1 & VCP & Jab1 & VCP \\
\hline 5 & ++ & ++ & - & - & - & - & - & - & - & - & - & - & - & + \\
\hline 15 & - & - & +++ & +++ & +++ & ++ & - & - & - & - & ++ & ++ & + & + \\
\hline 30 & - & - & +++ & +++ & ++ & ++ & ++ & ++ & ++ & ++ & ++ & ++ & ++ & ++ \\
\hline 60 & - & - & +++ & +++ & ++ & + & + & ++ & ++ & ++ & + & +++ & + & + \\
\hline
\end{tabular}

Semiquantitive evaluation of Jab1/CSN5 and p97/VCP immunoreactive cells in the developing rat testis. GC: Gonocytes, Sg: Spermatogonia, Sc: Spermatocyte, rSt: Round spermatid, eSt: Elongating spermatid, Se: Sertoli cell, I: Interstitial cells.

weak immunoreactivity: +, moderate immunoreactivity: ++, strong immunoreactivity: +++

epididymis (Figure 4D-L). On days 5 and 15, Jab1/CSN5 expression was relatively higher in the CS epididymis (Figure 4B-E); however, the CT epididymis presented increased expression in day 30 and 60 testes (Figure 4G, $4 \mathrm{~J})$. Spermatozoa showed weak immunostaining in the lumen of day 60 epididymes (Figure 4J-L).

\section{Colocalisation of Jab1/CSN5 and p97/VCP in the developing rat testis and epididymis}

To determine Jab1/CSN5 and p97/VCP colocalisation, double immunofluorescence was performed in the testicular (Figure 5) and epididymal tissues (Figure 6). In the 5-day-old rat testis, Jab1/CSN5 and p97/VCP were found to be colocalised in gonocytes (Figure 5A). In the 15-day-old rat testis, p97/VCP immunostaining was overlapped with Jab1/CSN5 in spermatogonia, spermatocytes and Sertoli cells (Figure 5B). Although p97/VCP and Jab1/CSN5 staining intensities indicated differences in day 30, cytoplasm of spermatocytes, Sertoli cells,

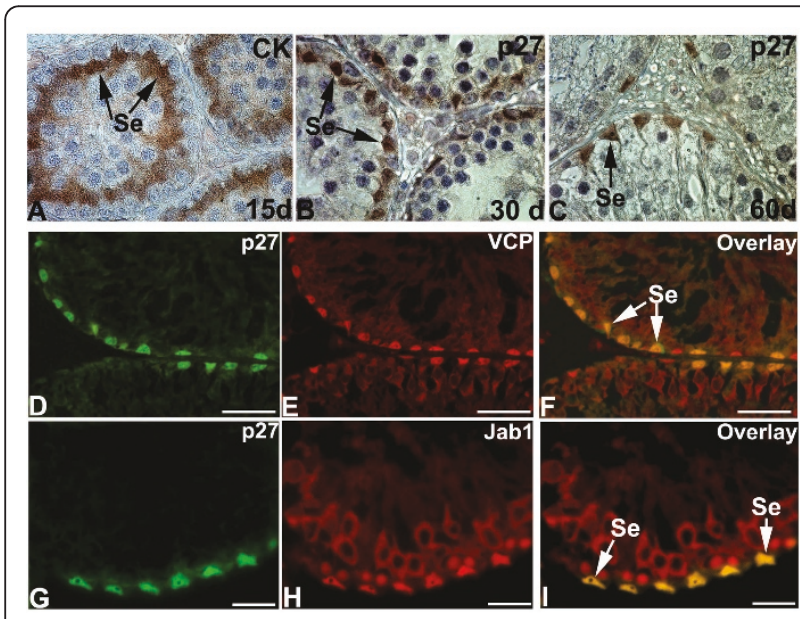

Figure 2 Immunohistochemical analysis of Sertoli cells at day 5 (A), 15 (B), 60 (C) and colocalisation of p97/VCP - p27 kip1 (D-F) and Jab1/CSN5 - p27 ${ }^{\text {kip1 }}$ (G-I) in rat testis. Cytokeratin $18(\mathrm{CK})$ are detected in immature Sertoli cells (Se) at day 15 (A) and $p 27^{\text {kip } 1}$ is observed in mature Sertoli cells (Se) of day 30 and 60 (B, C) in rat testis. Mature Sertoli cells (Se) are immunopositive for $\mathrm{p} 27^{\mathrm{kip} 1}$ (green, D, G), p97NCP (red, E) and Jab1/CSN5 (red, H), resulting in a yellow color (overlay, F, I). Scale bars: $25 \mu \mathrm{m}$. spermatogonia, round $(\mathrm{rSt})$ and elongating (eSt) spermatids were found to be immunopositive for Jab1/CSN5 and p97/VCP (Figure 5C). In the 60-day-old rat testis, spermatogonia, spermatocytes, Sertoli cells and elongating spermatids were found to be double immunopositive for Jab1/CSN5 and p97/VCP, although some Sertoli cells and spermatogonia showed only Jab1/CSN5 or p97/VCP immunpositivity (Figure 5D).

In the 5-day-old rat epididymis, Jab1/CSN5 and p97/ VCP were colocalised in the cytoplasm of the epithelial cells of corpus epididymis (Figure 6A). In the 15, 30 and 60-day-old rat epididymis, both proteins were found to colocalise in the nuclear and cytoplasmic regions (Figure 6B-D). Overall, the expression of Jab1/CSN5 and p97/VCP was gradually increased from 5 to 60 days of epididymis.

\section{Changes in protein expression levels of p97/VCP and} Jab1/CSN5 in the developing rat testis and epididymis In agreement with immunohistochemistry, Western blot results confirmed the presence of p97/VCP and Jab1/ CSN5 in the developing rat testis and epididymis. Western blot analyses revealed a specific band at $97 \mathrm{kDa}$ for p97/VCP and at $38 \mathrm{kDa}$ for Jab1/CSN5. The intensity of both bands was quantified and normalised for the intensity of $\beta$-actin controls (Figure 7A-B, lower panels). The expression level of p97/VCP was low on day 5 of testis and epididymis but increased and reached a peak on day 30. However, no significant changes were observed between 30 and 60-day-old rat testis for p97/VCP expression (Figure 7A). Jab1/CSN5 expression was also increased gradually but reached the peak on day 30 in testis and on day 60 in the epididymis (Figure 7A-B). In accordance with immunohistocehemical results, p97/ VCP and Jab1/CSN5 expressions were significantly higher in the CT epididymis compared to the CS and CA epididymis at day 30 and day 60 epididymis (Figure 7B, lower panel).

\section{Discussion}

To our knowledge, this is the first study demonstrating coexpression of the UPS components $\mathrm{p} 97 / \mathrm{VCP}$ and Jab1/CSN5 during postnatal development of the rat testis and epididymis using immunohistochemistry, 


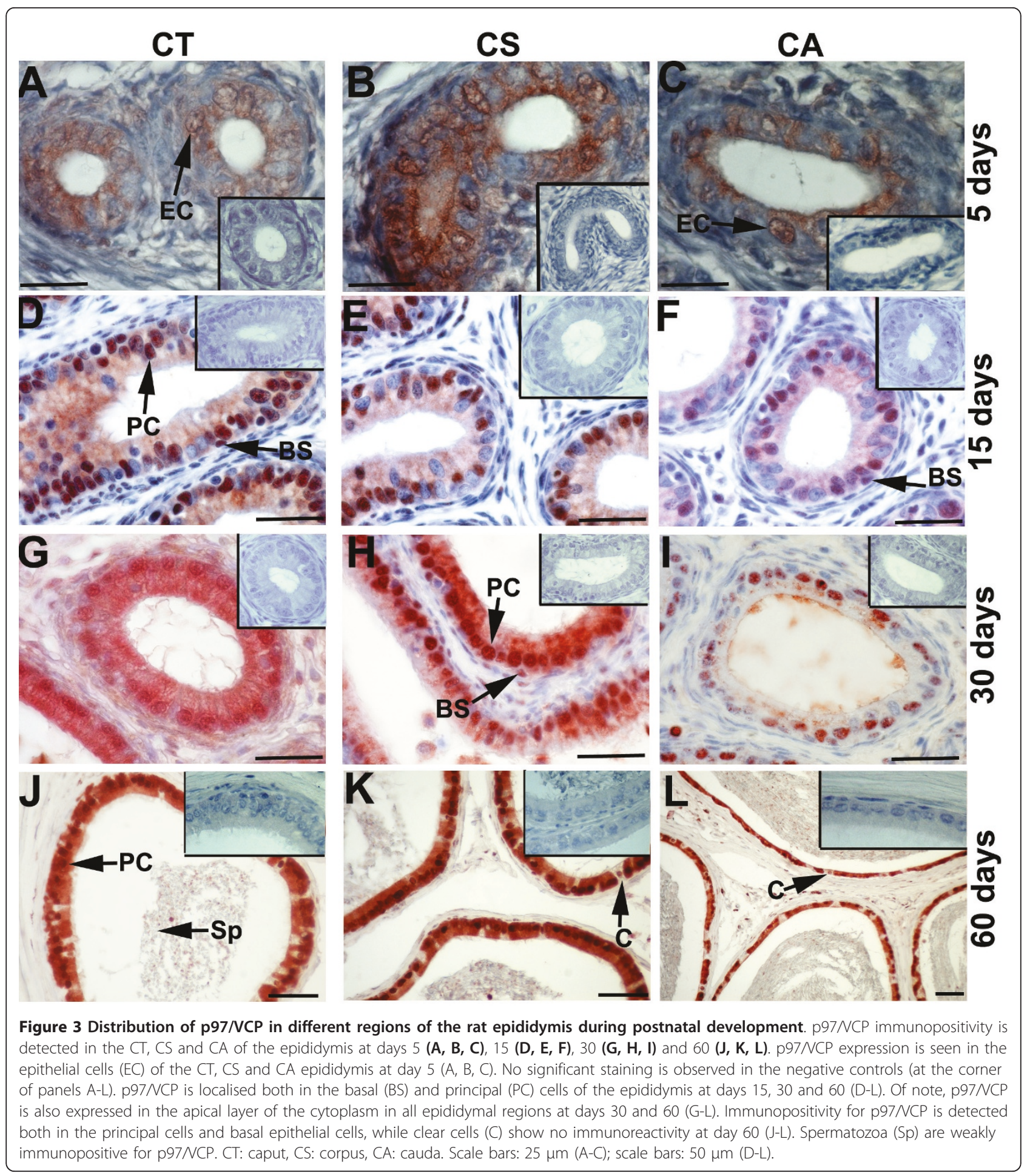

immunofluorescence and Western blotting. Our results indicate that p97/VCP expression overlapped with Jab1/ CSN5 expression in gonocytes, spermatogonia, spermatocytes, Sertoli cells, spermatids and epididymal epithelial cells in the 5-, 15-, 30- and 60-day-old rat testis and epididymis.
To define specific sites where p97/VCP and Jab1/ CSN5 expression might be important, we explored cellspecific expression of p97/VCP and Jab1/CSN5 in the developing rat testis and epididymis. In the 5-day-old rat testis, we observed that $\mathrm{p} 97 / \mathrm{VCP}$ and Jab1/CSN5 were specifically expressed in gonocytes and that the 
Table 2 Localisation of Jab1/CSN5 and p97/VCP in rat epididymis

\begin{tabular}{|c|c|c|c|c|c|c|c|c|c|c|c|c|}
\hline \multirow[b]{3}{*}{ Postnatal Day } & \multicolumn{4}{|c|}{ Caput } & \multicolumn{4}{|c|}{ Corpus } & \multicolumn{4}{|c|}{ Cauda } \\
\hline & \multicolumn{2}{|c|}{ PR } & \multicolumn{2}{|c|}{ BS } & \multicolumn{2}{|c|}{ PR } & \multicolumn{2}{|c|}{ BS } & \multicolumn{2}{|c|}{ PR } & \multicolumn{2}{|c|}{ BS } \\
\hline & Jab1 & VCP & Jab1 & VCP & Jab1 & VCP & Jab1 & VCP & Jab1 & VCP & Jab1 & VCP \\
\hline 5 & + & + & - & + & + & ++ & - & + & + & + & - & + \\
\hline 15 & + & + & + & ++ & ++ & ++ & + & ++ & + & + & + & + \\
\hline 30 & +++ & +++ & ++ & ++ & ++ & +++ & ++ & ++ & ++ & ++ & + & + \\
\hline 60 & +++ & +++ & +++ & +++ & +++ & +++ & +++ & +++ & ++ & ++ & ++ & ++ \\
\hline
\end{tabular}

Semiquantitive evaluation of Jab1/CSN5 and p97/NCP immunoreactive cells in the developing rat epididymis. PR: Principal cell, BS: Basal cell. weak immunoreactivity: +, moderate immunoreactivity: ++, strong immunoreactivity: +++

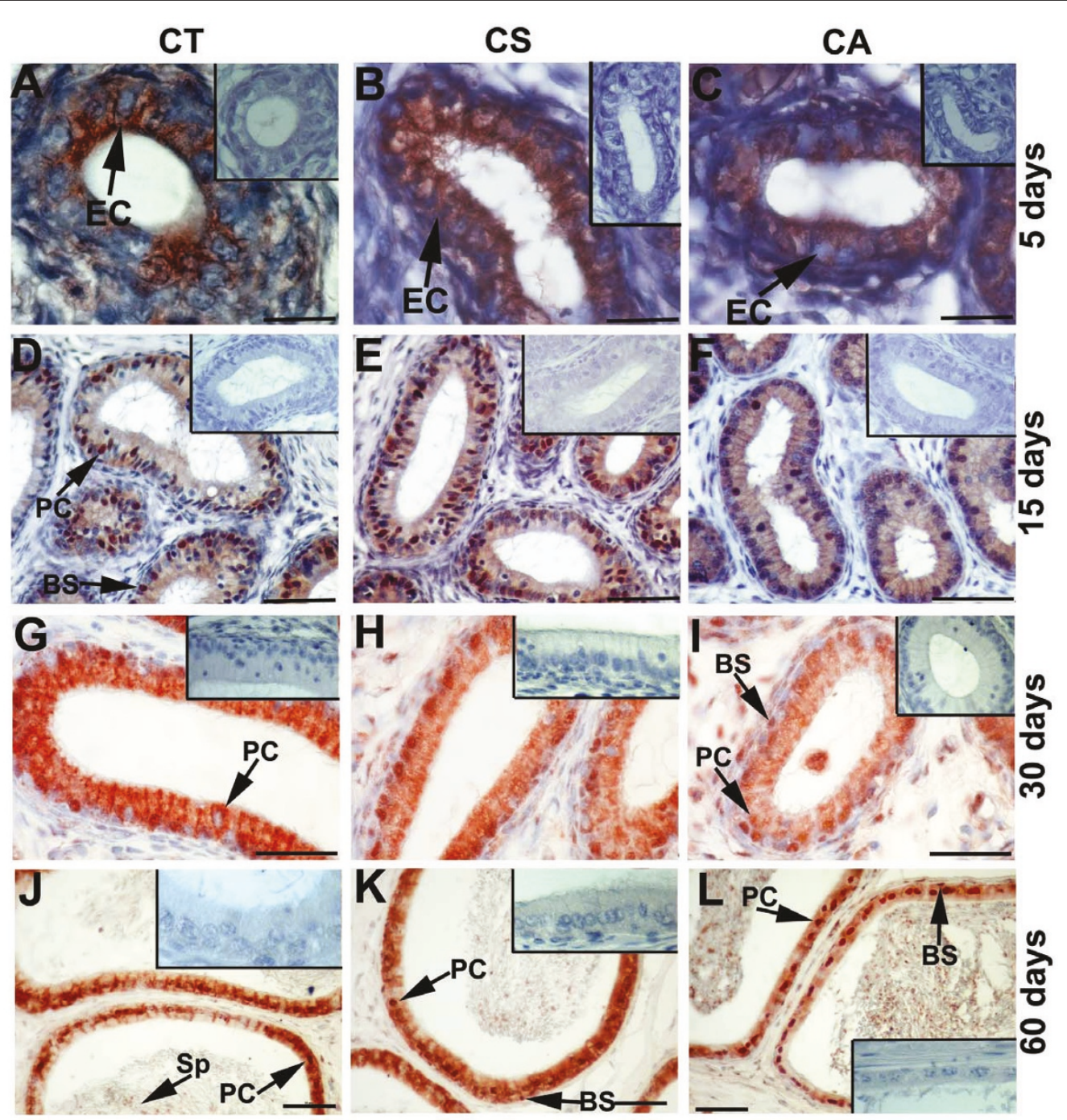

Figure 4 Distribution of Jab1/CSN5 in different regions of the rat epididymis during postnatal development. Jab1/CSN5 immunopositivity is detected in the CT, CS and CA at days 5 (A, B, C), 15 (D, E, F), $30(\mathbf{G}, \mathbf{H}, \mathbf{I})$ and 60 (J, K, L). Jab1/CSN5 is found in the cytoplasm of epithelial cells (EC) of the epididymis at day 5 ( $A, B, C)$. Both the basal (BS) and principal (PC) cells of the CT, CS and CA epididymis are found to be immunopositive for Jab1/CSN5 at days 15, 30 and 60 (D-L). In addition to the nuclear region of epithelial cells (EC), Jab1/CSN5 is highly expressed in the cytoplasm in the CT and CS epididymis at days 30 (G-I) and 60 (J-L). Spermatozoa (Sp) are weakly immunopositive for Jab1/CSN5 at day 60 (J-L). No significant staining is observed in the negative controls (at the upper corner of panels A-L). CT: caput, CS: corpus, CA: cauda. Scale bars: $25 \mu \mathrm{m}(\mathrm{A}-\mathrm{C})$; scale bars: $50 \mu \mathrm{m}$ (D-L). 


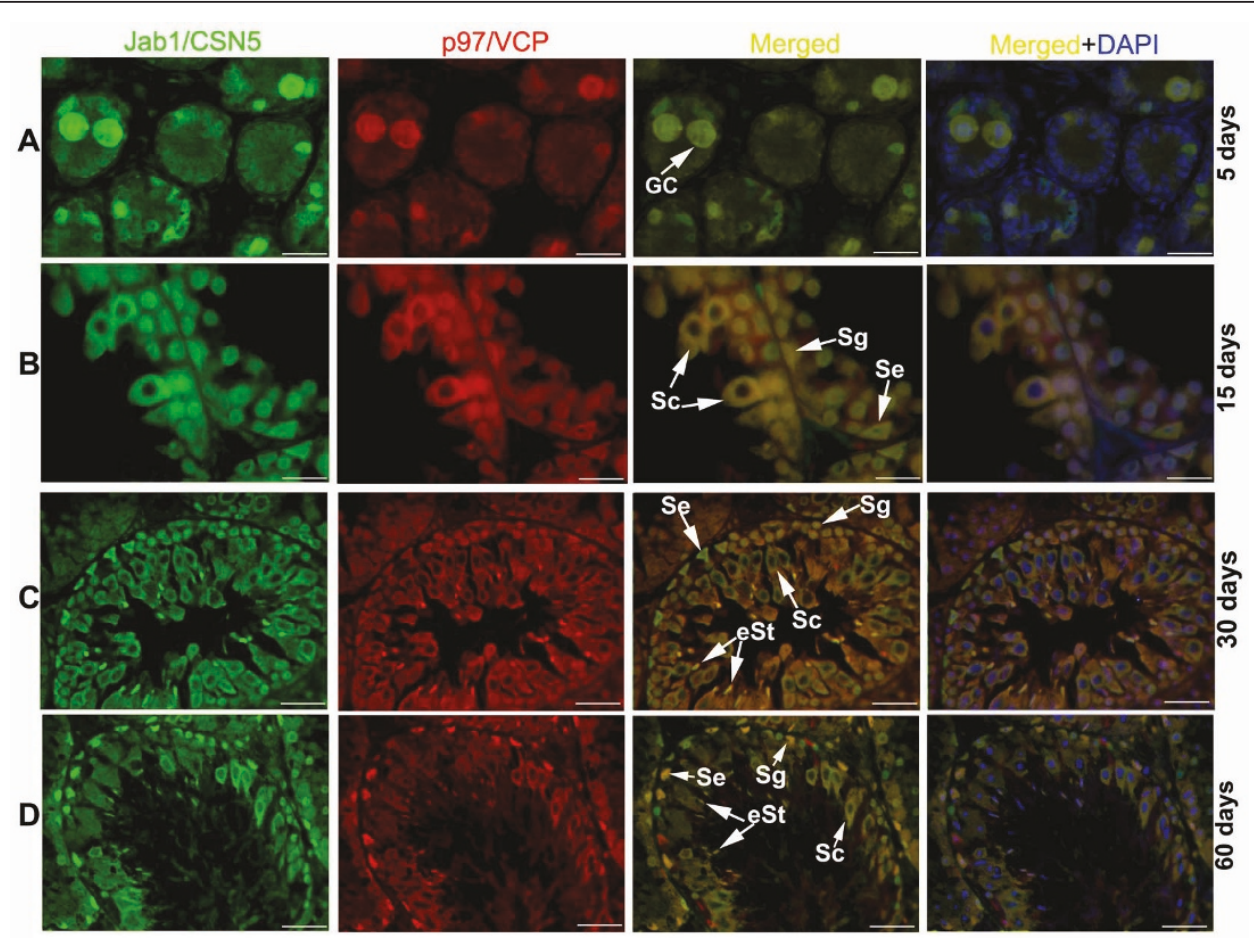

Figure 5 Double immunohistochemistry representing the colocalisation of p97/VCP and Jab1/CSN5 in the developing rat testis (A-D). Detection of Jab1/CSN5 (green), p97NCP (red), and double-stained (yellow) positive cells merged with DAPI nuclear staining on day 5 (A), day 15 (B), day 30 (C) and day 60 (D). A: Day 5 gonocytes (GC) are double labelled with p97NCP and Jab1/CSN5. B: Double-labelled spermatocytes (Sc), spermatogonia (Sg) and Sertoli cells (Se) are shown on day 15, and the nuclear regions of some spermatocytes are only positive for Jab1/ CSN5. C: Jab1/CSN5 and p97NCP positivity (yellow) is observed in spermatocytes (Sc), spermatogonia (Sg), Sertoli cells (Se) and elongating spermatids (eSt) on day 30. D: Double staining (yellow) is detected in the cytoplasm of spermatocytes (Sc), the nuclear region of spermatogonia (Sg) and elongating spermatids (eSt) and Sertoli cells (Se) in the 60-day-old rat testis. Scale bars: $25 \mu \mathrm{m}$.

expression levels of these proteins were significantly lower compared to what was seen at other ages. The low levels of p97/VCP and Jab1/CSN5 expression in the neonatal testis suggest that neither protein has a major role during very early postnatal stages. However, from day 5 after birth to day 30, the levels of the p97/VCP and Jab1/CSN5 expression significantly increased. It has previously been shown that the period from 4 days after birth to 6 weeks of age corresponds to a period of rapid cell proliferation and growth of the rat testis and epididymis [3]. Therefore, the gradual increase in the expression of p97/VCP and Jab1/CSN5 coincides with testicular growth, suggesting that the p97/VCP and Jab1/CSN5 proteins may play important roles in cell proliferation in the testis and epididymis. In fact, it is well known that Jab1/CSN5 plays an essential role in cell growth and that strong expression of Jab1/CSN5 is associated with accelerated proliferation [46].

During postnatal development, the rat testis is composed of several developmental stages [39]. The rat testis at postnatal days 0-5 only contains gonocytes and somatic cells. By days 6-7, spermatogonia appear. By day 13-23, spermatocytes are present, and round spermatids are first observed by day 24-25. At postnatal day 30, elongating spermatids are seen, and by day 36 , elongated spermatozoa can be found. In the present study, p97/ VCP and Jab1/CSN5 were found to exhibit notable expression in the rat testis and to be present at virtually every phase of germ cell development and maturation. Therefore, these proteins might have important roles in the developing rat testis and epididymis. For example, as shown by the staining presented in Figure 1 and Figure 5, p97/VCP and Jab1/CSN5 localised in round and elongating spermatids, where the proteins are included in the developing acrosome and the sperm tail. Additionally, both proteins were expressed in maturing spermatocytes and spermatogonia, suggesting that these proteins may also be critical for normal spermatocyte development. Moreover, p97/VCP and Jab1/CSN5 immunoreactivity appeared in the Sertoli cells of juvenile animals (15- and 30-day-old rats) and mature rats (60-day-old rats).

Ultrastructural investigations of Sertoli cell have revealed that numerous phagosomes are located in the cytoplasm of these cells, which indicates the occurrence of phagocytic activity [43]. These authors indicated that 


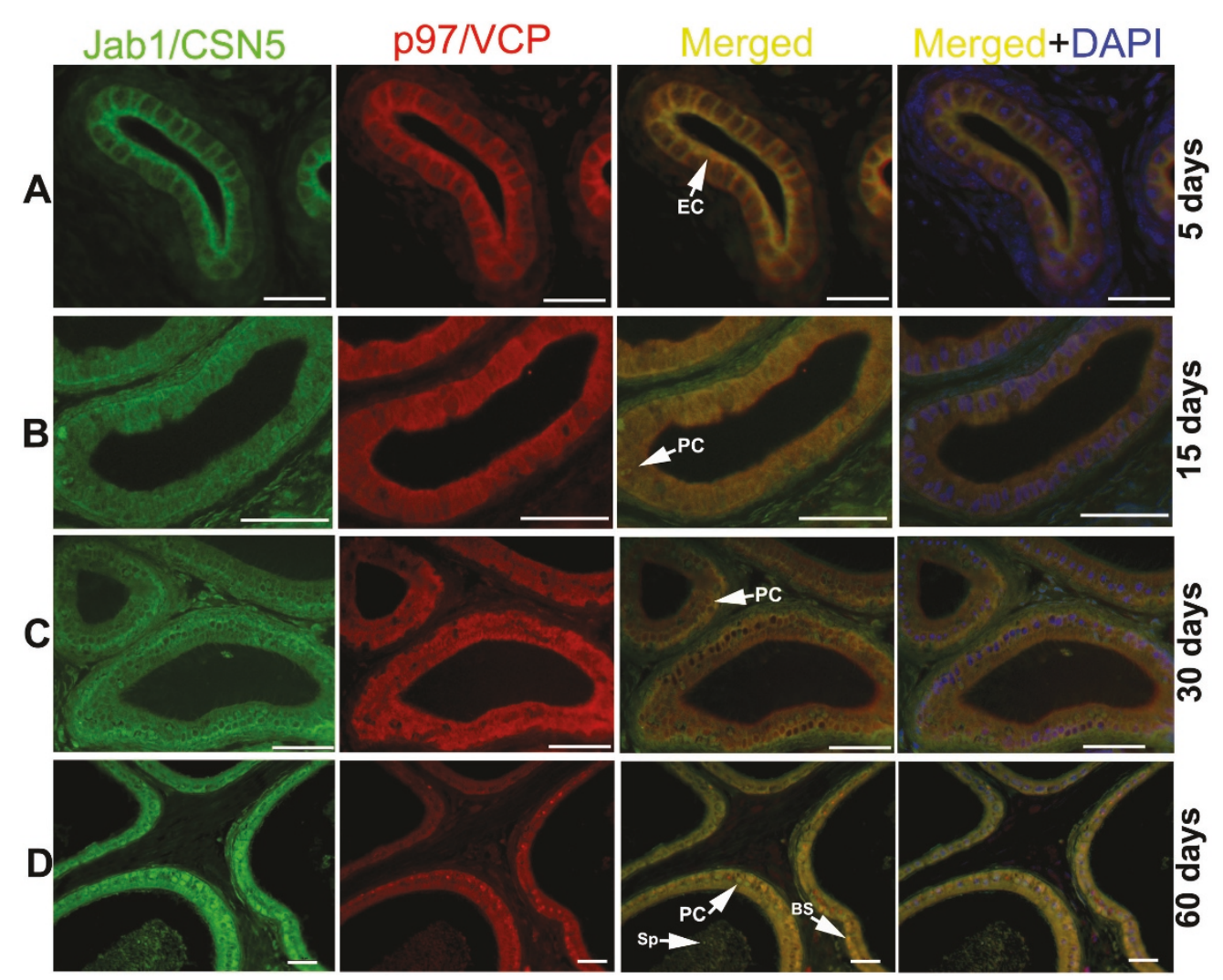

Figure 6 Colocalisations of Jab1/CSN5 and p97/VCP in the developing rat epididymis (A-D). Detection of Jab1/CSN5 (green), p97/VCP (red), and double (yellow) positive cells merged with DAPI nuclear staining on day 5 (A), 15 (B), 30 (C) and 60 (D) CS epididymis. Both the basal (BS) and principal cells (PC) of CS epididymis are immunopositive for Jab1/CSN5 (green) and for p97NCP (red), resulting a yellow color. Spermatozoa (Sp) are weakly immunopositive for Jab1/CSN5 and p97NCP on day 60. Scale bars: $25 \mu \mathrm{m}$ (A), 50 m (B-D).

Sertoli cells are highly involved in the digestion of germ cells that degenerate during spermatogenesis and of lobules of residual spermatid cytoplasm left during spermiation. Some researchers have also reported that Sertoli cells might be involved in the exchange and elimination of excessive sperm cell substances [47,48]. Recently, p97/VCP was found to be essential for autophagosome maturation, suggesting that $\mathrm{p} 97 / \mathrm{VCP}$ might be selectively required for autophagic degradation of ubiquitinated substrates $[24,25]$. Based on the localisation of the p97/VCP in immature and mature Sertoli cells, our results support previous observations, and we suggest that p97/VCP may be necessary for the processing of ubiqutinylated and misfolded proteins from larger protein complexes or membranes in Sertoli cells. Further functional studies will be required to clarify the physiological role of p97/VCP in Sertoli cells.

In the present study, it was found that the expression of p97/VCP and Jab1/CSN5 gradually increased during postnatal development of the rat epididymis. Moreover, both proteins were observed in the epididymal epithelium and produced by all regions of the epididymis but were highly expressed in the CT and CS epididymis. These findings also support the idea that p97/VCP and Jab1/CSN5 probably contribute to the sperm maturation process in the epididymis.

There are number of pieces of evidence that removal and degradation of defective spermatozoa occurs during epididymal passage $[8,16,49]$. However, it is not clear how the defective spermatozoa are removed or what components of the UPS contribute proteasomal proteolysis in the epididymis. One possibility that arises from the present study is that Jab1/CSN5 together with p97/ VCP may act as an important mediator during the proteasomal degradation of defective spermatozoa. It is well known that the JAMM domain of Jab1/CSN5 has deubiquitinase activity when associated with the CSN [36]. This activity of Jab1/CSN5 might be critical for protein degradation in the epididymis. Furthermore, it was previously shown when the CSN was inactivated by knockdown of Jab1/CSN5, the amount of polyubiquitinated proteins bound to $\mathrm{p} 97 / \mathrm{VCP}$ increased, indicating that the CSN is required for proper processing of substrate proteins bound to p97/VCP [29]. Clearly, p97/VCP and 
A
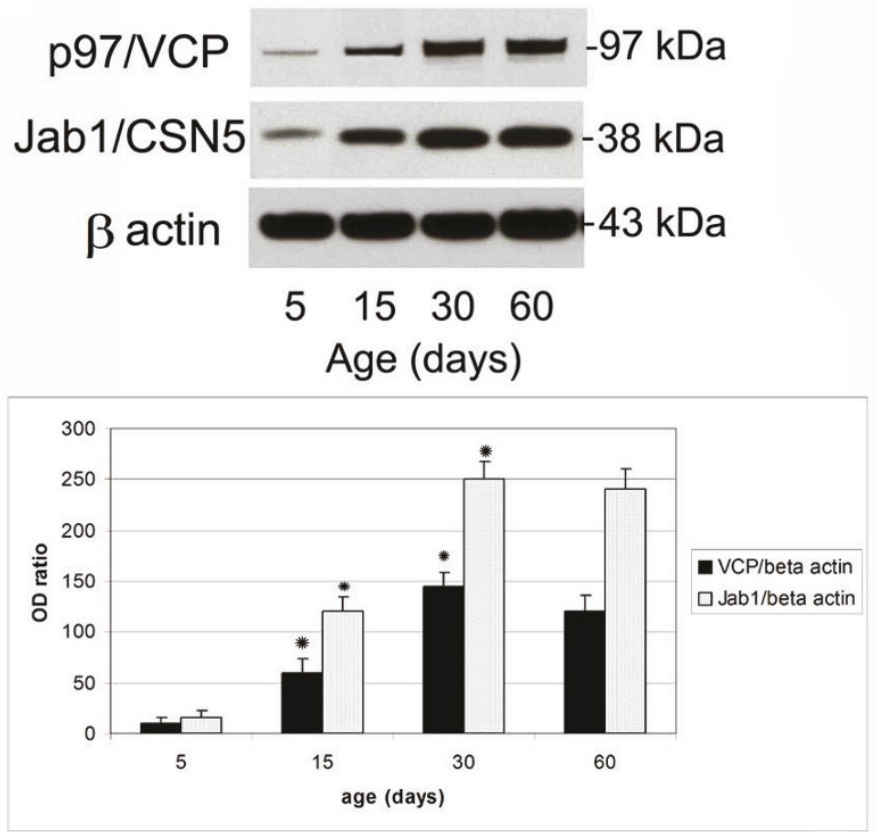

B
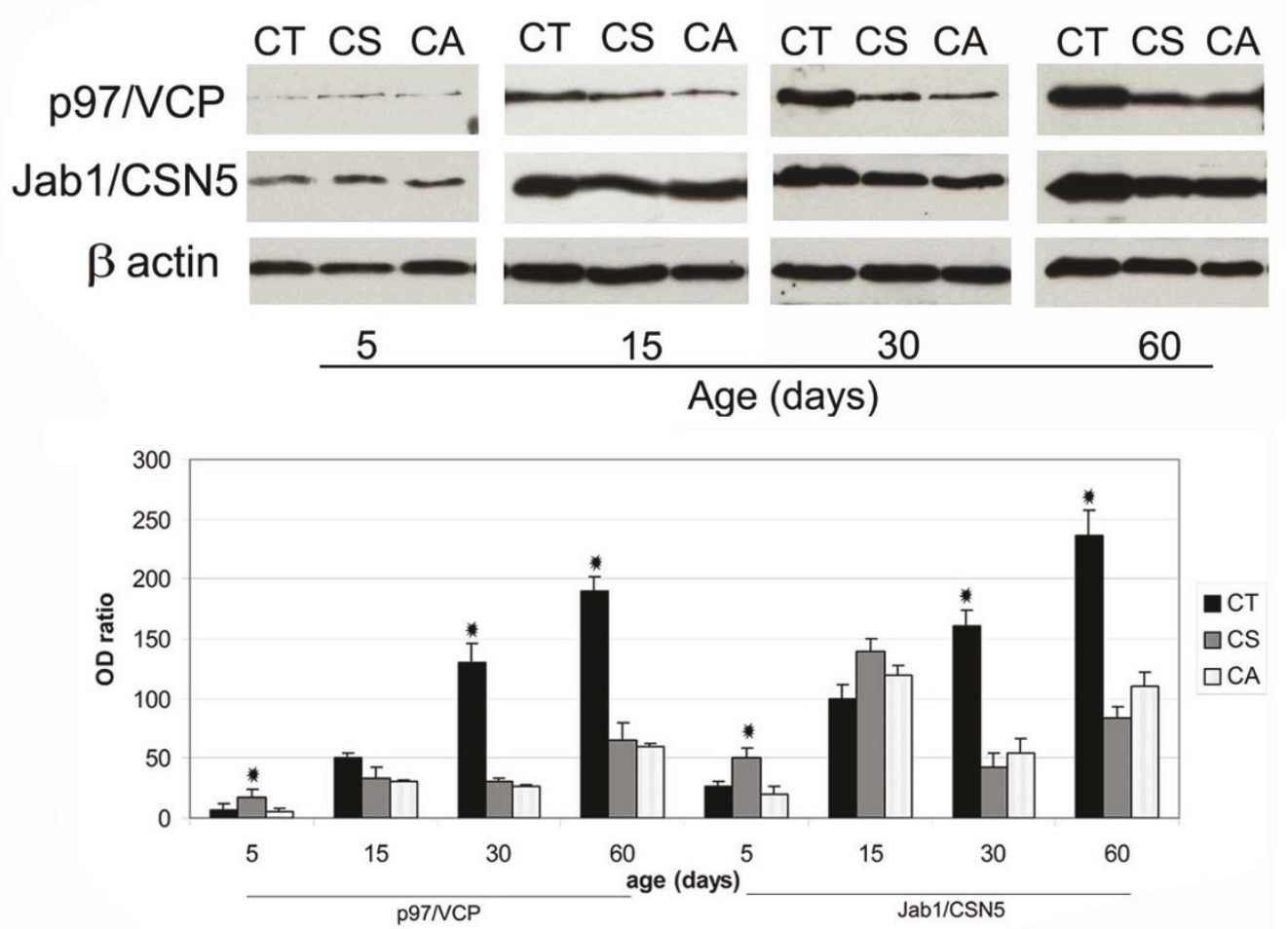

Figure 7 Western blot analysis of p97/VCP and Jab1/CSN5 in the developing rat testis (A) and epididymis (B). A: p97/NCP (97 kDa) and Jab1/CSN5 (38 kDa) were detected by western blotting. $\beta$-actin ( $43 \mathrm{kDa}$ ) was used as loading control. Immunoblot bands were quantified by an optical densitometer. The OD (optical density) values of the p97NCP and Jab1/CSN5 bands were normalised to the OD values of $\beta$-actin bands. The data in the graphs are presented as the means \pm SEM. The expression of p97NCP and Jab1/CSN5 is significantly increased from days 5 to 30 in the testis (Asterisks indicate, $p<0.05$ ); however, no differences are observed between days 30 and 60. B: p97NCP and Jab1/CSN5 expression levels are significantly higher in the CT epididymis than the CS and CA epididymis at days 30 and 60 . Asterisks indicate $p<0.05$, days 5 CS vs. days 5 CA and CT epididymis, days 30 and 60 CT vs. days 30 and 60 CA and CS epididymis. CT: caput, CS: corpus, CA: cauda. 
Jab1/CSN5 may also be involved in the proper processing of polyubiquitinated substrates in the epididymis. Moreover, the colocalisation of p97/VCP and Jab1/ CSN5 in 5-, 15-, and 30-day-old rat testes and epididymes also supports the previous findings indicating that Jab1/CSN5 may regulate the ubiquitination status of proteins bound to $\mathrm{p} 97 / \mathrm{VCP}$.

\section{Conclusions}

Here, we report the developmental expression and colocalisation of the UPS components p97/VCP and Jab1/ CSN5 in the rat testis and epididymis. Further research might contribute to the clarification of the exact functions of these proteins in the development of the rat testis and epididymis.

\section{Acknowledgements}

This work was partially supported by the Research Foundation of Gaziosmanpasa University (2011/08). We would like to thank Dr. Ahmet Eyibilen for generously providing AEC chromogen and Dr. Emin Turkay Korgun for providing p $27^{\mathrm{kip} 1}$ antibody. This manuscript was edited by Elsevier Language Editing Services.

\section{Author details}

'Department of Histology and Embryology, Faculty of Medicine, Gaziosmanpasa University, Tokat, Turkey. ${ }^{2}$ Department of Urology, Faculty of Medicine, Gaziosmanpasa University, Tokat, Turkey. ${ }^{3}$ Department of Anatomy, Faculty of Medicine, Gaziosmanpasa University, Tokat, Turkey. ${ }^{4}$ Experimental Animal Center, Faculty of Medicine, Gaziosmanpasa University, Tokat, Turkey.

\section{Authors' contributions}

SC and SO performed the major part of the histological analysis and wrote the manuscript. FE, TY, ZK, UT and HA participated in the study design and the analysis. All authors read and approved the final manuscript.

\section{Competing interests}

The authors declare that they have no competing interests.

Received: 27 May 2011 Accepted: 19 August 2011

Published: 19 August 2011

\section{References}

1. de Kretser DM: Clinical male infertility. I. Prevalence of and progress in understanding male infertility. Reprod Fertil Dev 1994, 6:3-8.

2. Kierszenbaum AL: Mammalian spermatogenesis in vivo and in vitro: a partnership of spermatogenic and somatic cell lineages. Endocr Rev 1994, 15:116-134.

3. Clermont Y, Perey B: Quantitative study of the cell population of the seminiferous tubules in immature rats. Am J Anat 1957, 100:241-267.

4. Cooper TG: Interactions between epididymal secretions and spermatozoa. J Reprod Fertil Suppl 1998, 53:119-136.

5. Orgebin-Crist MC: Studies on the function of the epididymis. Biol Reprod 1969, 1(Suppl 1):155-175

6. Hinton BT, Palladino MA, Rudolph D, Labus JC: The epididymis as protector of maturing spermatozoa. Reprod Fertil Dev 1995, 7:731-745.

7. Sutovsky P, Moreno R, Ramalho-Santos J, Dominko T, Thompson WE, Schatten G: A putative, ubiquitin-dependent mechanism for the recognition and elimination of defective spermatozoa in the mammalian epididymis. J Cell Sci 2001, 114:1665-1675.

8. Sutovsky P: Ubiquitin-dependent proteolysis in mammalian spermatogenesis, fertilization, and sperm quality control: killing three birds with one stone. Microsc Res Tech 2003, 61:88-102.

9. Glickman $\mathrm{MH}$, Ciechanover A: The ubiquitin-proteasome proteolytic pathway: destruction for the sake of construction. Physiol Rev 2002, 82:373-428.
10. Bedard N, Hingamp P, Pang Z, Karaplis A, Morales C, Trasler J, Cyr D, Gagnon C, Wing SS: Mice lacking the UBC4-testis gene have a delay in postnatal testis development but normal spermatogenesis and fertility. Mol Cell Biol 2005, 25:6346-6354.

11. Liu Z, Oughtred R, Wing SS: Characterization of E3Histone, a novel testis ubiquitin protein ligase which ubiquitinates histones. Mol Cell Biol 2005, 25:2819-2831.

12. Wing SS: Deubiquitinating enzymes-the importance of driving in reverse along the ubiquitin-proteasome pathway. Int J Biochem Cell Biol 2003, 35:590-605.

13. Roest HP, van Klaveren J, de Wit J, van Gurp CG, Koken MH, Vermey M, van Roijen JH, Hoogerbrugge JW, Vreeburg JT, Baarends WM, et al: Inactivation of the HR6B ubiquitin-conjugating DNA repair enzyme in mice causes male sterility associated with chromatin modification. Cell 1996, 86:799-810.

14. Kwon J, Mochida K, Wang YL, Sekiguchi S, Sankai T, Aoki S, Ogura A, Yoshikawa Y, Wada K: Ubiquitin C-terminal hydrolase L-1 is essential for the early apoptotic wave of germinal cells and for sperm quality control during spermatogenesis. Biol Reprod 2005, 73:29-35.

15. Baarends WM, Roest HP, Grootegoed JA: The ubiquitin system in gametogenesis. Mol Cell Endocrinol 1999, 151:5-16

16. Baska KM, Manandhar G, Feng D, Agca Y, Tengowski MW, Sutovsky M, Yi YJ Sutovsky P: Mechanism of extracellular ubiquitination in the mammalian epididymis. J Cell Physiol 2008, 215:684-696.

17. Hochstrasser M: Ubiquitin, proteasomes, and the regulation of intracellular protein degradation. Curr Opin Cell Biol 1995, 7:215-223.

18. Kondo H, Rabouille C, Newman R, Levine TP, Pappin D, Freemont P, Warren G: p47 is a cofactor for p97-mediated membrane fusion. Nature 1997, 388:75-78.

19. Hirabayashi M, Inoue K, Tanaka K, Nakadate K, Ohsawa Y, Kamei Y, Popiel AH, Sinohara A, Iwamatsu A, Kimura Y, et al: VCP/p97 in abnormal protein aggregates, cytoplasmic vacuoles, and cell death, phenotypes relevant to neurodegeneration. Cell Death Differ 2001, 8:977-984.

20. Rabinovich E, Kerem A, Frohlich KU, Diamant N, Bar-Nun S: AAA-ATPase p97/Cdc48p, a cytosolic chaperone required for endoplasmic reticulumassociated protein degradation. Mol Cell Biol 2002, 22:626-634.

21. Meyer HH, Shorter JG, Seemann J, Pappin D, Warren G: A complex of mammalian ufd 1 and npl4 links the AAA-ATPase, p97, to ubiquitin and nuclear transport pathways. Embo J 2000, 19:2181-2192.

22. Hetzer M, Meyer HH, Walther TC, Bilbao-Cortes D, Warren G, Mattaj IW: Distinct AAA-ATPase p97 complexes function in discrete steps of nuclear assembly. Nat Cell Biol 2001, 3:1086-1091.

23. Ficarro S, Chertihin O, Westbrook VA, White F, Jayes F, Kalab P, Marto JA Shabanowitz J, Herr JC, Hunt DF, Visconti PE: Phosphoproteome analysis of capacitated human sperm. Evidence of tyrosine phosphorylation of a kinase-anchoring protein 3 and valosin-containing protein/p97 during capacitation. J Biol Chem 2003, 278:11579-11589.

24. Krick R, Bremer S, Welter E, Schlotterhose P, Muehe Y, Eskelinen EL, Thumm M: Cdc48/p97 and Shp1/p47 regulate autophagosome biogenesis in concert with ubiquitin-like Atg8. J Cell Biol 2010 190:965-973.

25. Tresse E, Salomons FA, Vesa J, Bott LC, Kimonis V, Yao TP, Dantuma NP, Taylor JP: VCP/p97 is essential for maturation of ubiquitin-containing autophagosomes and this function is impaired by mutations that cause IBMPFD. Autophagy 2010, 6:217-227.

26. Dai RM, Li CC: Valosin-containing protein is a multi-ubiquitin chaintargeting factor required in ubiquitin-proteasome degradation. Nat Cell Biol 2001, 3:740-744.

27. Meusser B, Hirsch C, Jarosch E, Sommer T: ERAD: the long road to destruction. Nat Cell Biol 2005, 7:766-772.

28. Klein JB, Barati MT, Wu R, Gozal D, Sachleben LR Jr, Kausar H, Trent JO, Gozal E, Rane MJ: Akt-mediated valosin-containing protein 97 phosphorylation regulates its association with ubiquitinated proteins. $J$ Biol Chem 2005, 280:31870-31881.

29. Cayli S, Klug J, Chapiro J, Froehlich S, Krasteva G, Orel L, Meinhardt A: The COP9 signalosome interacts ATP-dependently with p97/VCP and controls the ubiquitination status of proteins bound to p97/VCP. J Biol Chem 2009, 284:34944-34953.

30. Berse M, Bounpheng M, Huang X, Christy B, Pollmann C, Dubiel W: Ubiquitin-dependent degradation of Id 1 and Id 3 is mediated by the COP9 signalosome. J Mol Biol 2004, 343:361-370. 
31. Yun J, Tomida A, Andoh T, Tsuruo T: Interaction between glucoseregulated destruction domain of DNA topoisomerase llalpha and MPN domain of Jab1/CSN5.J Biol Chem 2004, 279:31296-31303.

32. Callige M, Kieffer I, Richard-Foy H: CSN5/Jab1 is involved in liganddependent degradation of estrogen receptor $\{a l p h a\}$ by the proteasome. Mol Cell Biol 2005, 25:4349-4358.

33. Li S, Liu X, Ascoli M: p38JAB1 binds to the intracellular precursor of the lutropin/choriogonadotropin receptor and promotes its degradation. J Biol Chem 2000, 275:13386-13393.

34. Kim BC, Lee HJ, Park SH, Lee SR, Karpova TS, McNally JG, Felici A, Lee DK, Kim SJ: Jab1/CSN5, a component of the COP9 signalosome, regulates transforming growth factor beta signaling by binding to Smad7 and promoting its degradation. Mol Cell Biol 2004, 24:2251-2262.

35. Wan M, Cao X, Wu Y, Bai S, Wu L, Shi X, Wang N: Jab1 antagonizes TGFbeta signaling by inducing Smad4 degradation. EMBO Rep 2002, 3:171-176.

36. Cope GA, Suh GS, Aravind L, Schwarz SE, Zipursky SL, Koonin EV, Deshaies RJ: Role of predicted metalloprotease motif of Jab1/Csn5 in cleavage of Nedd8 from Cul1. Science 2002, 298:608-611.

37. Shackleford TJ, Claret FX: JAB1/CSN5: a new player in cell cycle control and cancer. Cell Div 2010, 5:26

38. Leblond $C P$, Clermont $Y$ : Definition of the stages of the cycle of the seminiferous epithelium in the rat. Ann N Y Acad Sci 1952, 55:548-573.

39. Malkov M, Fisher $Y$, Don J: Developmental schedule of the postnatal rat testis determined by flow cytometry. Biol Reprod 1998, 59:84-92.

40. Parvinen M: Regulation of the seminiferous epithelium. Endocr Rev 1982, 3:404-417.

41. Griswold MD: Interactions between germ cells and Sertoli cells in the testis. Biol Reprod 1995, 52:211-216.

42. Cheng CY, Mruk DD: The biology of spermatogenesis: the past, present and future. Philos Trans R Soc Lond B Biol Sci 2010, 365:1459-1463.

43. Hutchison GR, Scott HM, Walker M, McKinnell C, Ferrara D, Mahood IK, Sharpe RM: Sertoli cell development and function in an animal model of testicular dysgenesis syndrome. Biol Reprod 2008, 78:352-360.

44. Sharpe RM, McKinnell C, Kivlin C, Fisher JS: Proliferation and functional maturation of Sertoli cells, and their relevance to disorders of testis function in adulthood. Reproduction 2003, 125:769-784.

45. Kayisli UA, Cayli S, Seval Y, Tertemiz F, Huppertz B, Demir R: Spatial and temporal distribution of Tie-1 and Tie-2 during very early development of the human placenta. Placenta 2006, 27:648-659.

46. Bounpheng MA, Melnikova IN, Dodds SG, Chen H, Copeland NG, Gilbert DJ, Jenkins NA, Christy BA: Characterization of the mouse JAB1 CDNA and protein. Gene 2000, 242:41-50.

47. Sakai Y, Nakamoto T, Yamashina S: Dynamic changes in Sertoli cell processes invading spermatid cytoplasm during mouse spermiogenesis. Anat Rec 1988, 220:51-57.

48. Russell LD, Tallon-Doran M, Weber JE, Wong V, Peterson RN: Threedimensional reconstruction of a rat stage V Sertoli cell: III. A study of specific cellular relationships. Am J Anat 1983, 167:181-192.

49. Tengowski MW, Feng D, Sutovsky M, Sutovsky P: Differential expression of genes encoding constitutive and inducible 205 proteasomal core subunits in the testis and epididymis of theophylline- or 1,3dinitrobenzene-exposed rats. Biol Reprod 2007, 76:149-163.

doi:10.1186/1477-7827-9-117

Cite this article as: Cayli et al:: Developmental expression of p97/VCP (Valosin-containing protein) and Jab1/CSN5 in the rat testis and epididymis. Reproductive Biology and Endocrinology 2011 9:117.

\section{Submit your next manuscript to BioMed Central and take full advantage of:}

- Convenient online submission

- Thorough peer review

- No space constraints or color figure charges

- Immediate publication on acceptance

- Inclusion in PubMed, CAS, Scopus and Google Scholar

- Research which is freely available for redistribution

Submit your manuscript at www.biomedcentral.com/submit
Biomed Central 